\title{
Sústalinable

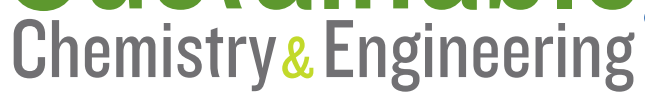 \\ Particle Size Distribution Effect on Cassava Starch and Cassava Bagasse Biocomposites
}

\author{
Florencia Versino ${ }^{* \dagger, \ddagger(0)}$ and María A. García ${ }^{* \dagger, \S}$ \\ ${ }^{\dagger}$ Centro de Investigación y Desarrollo en Criotecnología de Alimentos (CIDCA), UNLP-CONICET-CICPBA, 47 y 116, La Plata, \\ Buenos Aires 1900, Argentina \\ ${ }^{\ddagger}$ Departamento de Ingeniería Química, Facultad de Ingeniería, Universidad Nacional de La Plata (UNLP), 47 y 115 , La Plata, \\ Buenos Aires 1900, Argentina \\ ${ }^{\S}$ Departamento de Química, Facultad de Ciencias Exactas, Universidad Nacional de La Plata (UNLP), 47 y 115, La Plata, Buenos \\ Aires 1900, Argentina
}

Supporting Information

ABSTRACT: Regarding the growing interest in the development of biodegradable films from renewable sources, this work is focused on the utilization of cassava roots bagasse as a natural filler of cassava starch films. Homogenous films could be obtained by casting molding from gelatinized cassava starch suspensions, plasticized with glycerol and containing $1.5 \% \mathrm{w} / \mathrm{w}$ bagasse. In order to study the particle size effect on films properties, three different fibrous residue fractions (particles sized between 500$250,250-53$, and particles $<53 \mu \mathrm{m}$ ) were used and compared to films reinforced with bagasse particles sized under $500 \mu \mathrm{m}$. Chemical composition and particle size distribution of cassava bagasse helped to explain the starch films morphology and mechanical and barrier properties modifications. SEM micrographs evidenced that the filler was structurally incorporated in the matrix, reinforcing cassava-starch matrices regardless of bagasse particle size. The filler increased the UV-barrier capacity and opacity of the materials, though water vapor permeability increased with solids content and filler particle size. Moreover, the developed biocomposite materials can be heat-sealed, indicating their suitability for flexible packaging manufacture. Even though starch-based materials are essentially biodegradable, the biodegradation kinetics of the reinforced biocomposites was studied showing the slowest degradation process for materials with larger filler particles.

KEYWORDS: Biocomposites, Renewable materials, Biodegradable, Fibrous fillers, Particle size

\section{INTRODUCTION}

Biocomposites are obtained by the combination of a biodegradable polymer as the matrix material and natural fillers (e.g., lignocellulosic fillers). Consequently, since both components are biodegradable, the resulting composite is also generally expected to be biodegradable. ${ }^{1}$ Due to the growing concerns over environment conservation and sustainability issues, this century has witnessed noteworthy developments in green polymer science through the development of biocomposites. $^{2}$ Within this type of materials, natural fiberspolymer composites have become an attractive alternative from both economic and ecological points of view. ${ }^{3}$ In general, the main advantages of vegetal fibers are their abundance, low density, high specific stiffness, and natural biodegradability. ${ }^{4}$

Natural fibers are derived either directly from agricultural sources, such as cotton, jute or sisal, or as a processing or production residues when crops are processed for their primary uses, mainly for the food industry. ${ }^{5}$ In this respect, the utilization of biobased byproducts, waste, or residues derived from industrial processes as reinforcements in biocomposites appears to be a promising alternative to develop affordable, sustainable, and resilient new composite materials with adequate properties for diverse applications. Research and development on products and manufacturing processes aiming to mitigate environmental damages are being supported by legislative provisions, an important factor influencing the future prospects of natural fibers based biocomposites. ${ }^{6}$

Notwithstanding their potential as reinforcing agents, natural fibers present some disadvantages that must be contemplated. These fillers are typically hydrophilic, hence are incompatible with hydrophobic polymer matrices and show poor resistance to moisture, and in comparison with inorganic fibers they have lower durability and limited thermal and structural stability. $^{6-10}$ Traditionally, these problems have been at least

Received: September 14, 2018

Revised: November 6, 2018

Published: November 15, 2018 
a

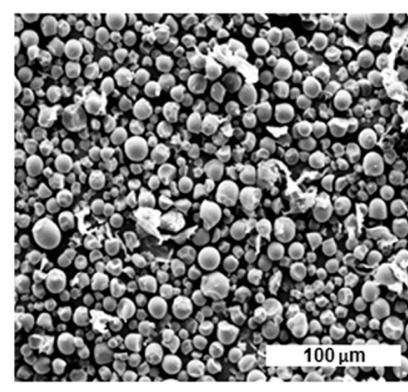

b

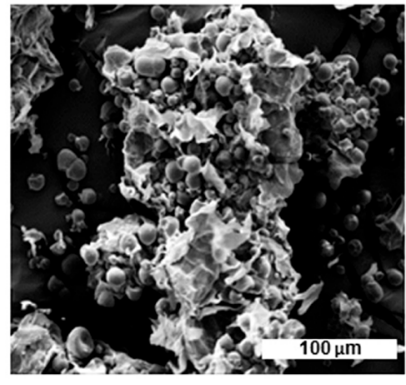

C

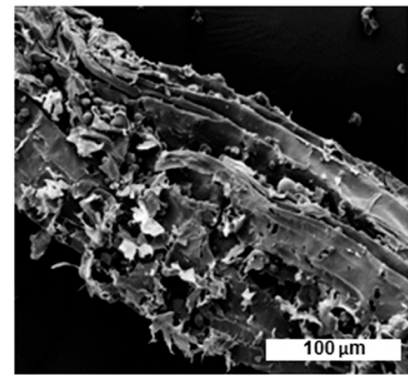

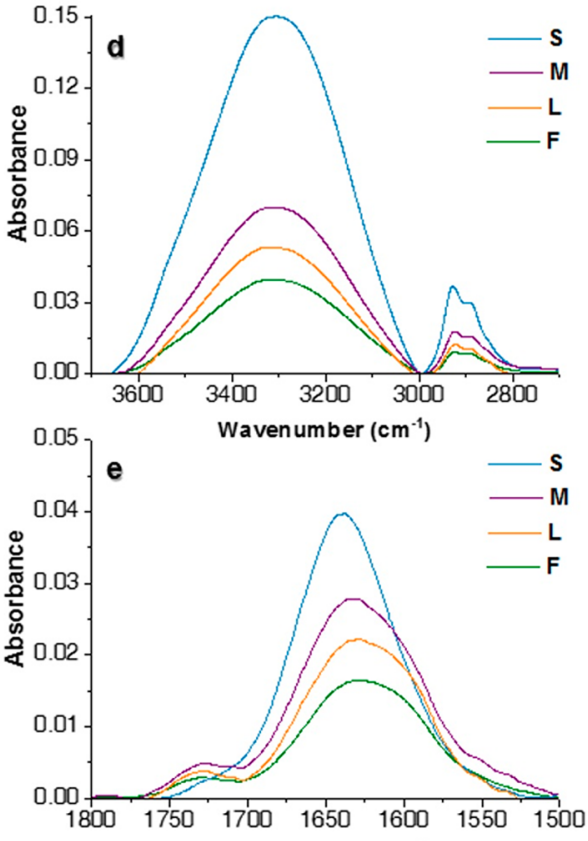

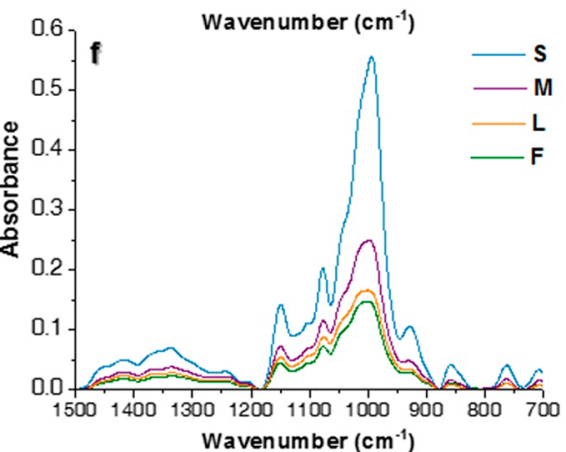

Figure 1. SEM micrograph $(1000 \times)$ of the different fractions of cassava bagasse: (a) S, (b) M, and (c) L. FTIR-ATR spectra of the different particle size fractions of ground bagasse filling (S, M, L, and F): (d) region $3700-2700 \mathrm{~cm}^{-1}$, (e) region $1800-1500 \mathrm{~cm}^{-1}$, and (f) region $1500-$ $700 \mathrm{~cm}^{-1}$.

partially addressed by adequate physical and chemical modifications, though such methods increase production costs. ${ }^{6}$ Moreover, the aforementioned issues, alongside with the fibers tendency to form aggregates during processing, derive in difficulties in adapting their incorporation to conventional manufacturing processes. However, these can be effectively solved by appropriate material selection, including raw material properties, size, and shape. ${ }^{11}$ Consequently, to optimize the characteristics of the composite materials obtained, it is necessary to consider the size of the filler used. The particle size, as well as the chemical nature and surface characteristics of the reinforcement affect the interactions between the reinforcement and the matrix, which directly affects the properties of the materials obtained. $^{12,13}$

As has been demonstrated by other authors, besides filler nature and size, the reinforcing agent content has an important impact on biobased composites mean properties. ${ }^{1,14}$ In a previous work, cassava starch-reinforced films were developed by the casting technique, and its formulation was optimized. ${ }^{15}$ The filler agent used was the bagasse remaining from the cassava starch extraction process dried, crushed, and sieved through a $500 \mu \mathrm{m}$ sieve. The reinforcement of the film matrices was demonstrated, especially through the increment in the mechanical resistance and the elastic modulus. Likewise, cassava peels and bagasse were investigated as fillers of films obtained by thermocompression. ${ }^{16}$ Thus, the main objective of the present work was to analyze the effect of the filler particle size on the properties of cassava starch films reinforced with the bagasse remaining from the starch extraction process.

To achieve a more sustainable approach, all materials require a tuned balance between their performance during service life and their degradation behavior after use. ${ }^{17}$ Therefore, biocomposites design should guarantee a correct end-of-life of the biobased goods. Although it is known that starch-based materials are essentially biodegradable, it is important to study the kinetics of this process since it could limit certain potential applications, for instance, soil cover in short cycle crops. Subsequently, in-land biodegradation experiments of the developed cassava starch-based biocomposites were conducted, with the ultimate objective to evaluate if the bagasse filler particle size affected the materials biodegradability kinetics.

\section{EXPERIMENTAL SECTION}

Materials. Cassava roots (Manihot esculenta) were provided by the INTA Montecarlo Experimental Station farm $\left(26^{\circ} 33^{\prime} 40.15^{\prime \prime} \mathrm{S}\right.$ and $54^{\circ} 40^{\prime} 20.06^{\prime \prime} \mathrm{W}$, Misiones, Argentina). Starch and bagasse were obtained as described previously. ${ }^{18}$ The fibrous residue was dried, crushed, and sieved (through a $500 \mu \mathrm{m}$ mesh sieve) and later 
separated into different particle size fractions: $\mathrm{L}, 500-250 \mu \mathrm{m} ; \mathrm{M}$, $250-53 \mu \mathrm{m}$; and $\mathrm{S},<53 \mu \mathrm{m}$. These fractions were separated through a vibratory sieve (ALEIN International, Argentina) with three ASTM standard mesh sizes of 500, 250, and $53 \mu \mathrm{m}$. Each bagasse powder fraction was recovered between two sieves (or the last sieve and the base). The whole fraction, including all particle sizes under $500 \mu \mathrm{m}$ named F, was also used for comparison. The cassava bagasse chemical composition and particle size distribution had been characterized in a previous work. ${ }^{16}$ The particle size ranges for each fraction herein studied ( $\mathrm{L}, \mathrm{M}$, and $\mathrm{S}$ ) were selected considering similar mass fraction.

Preparation of Films. Aqueous suspensions of 3\% w/w starch with $1.5 \% \mathrm{w} / \mathrm{w}$ of different size fractions of the fibrous filler were gelatinized at $90{ }^{\circ} \mathrm{C}$ for $20 \mathrm{~min}$. Glycerol was added as a plasticizer to the gelatinized suspensions $(25 \mathrm{~g} / 100 \mathrm{~g}$ of starch), which were later dried in Petri dishes in a ventilated oven at $50{ }^{\circ} \mathrm{C}$ for $4 \mathrm{~h}$. In the same way, two control films without filler were prepared for comparison purposes: one with the same starch content $\left(\mathrm{C}_{3}=3 \% \mathrm{w} / \mathrm{w}\right)$ and others with the same total solids content like the reinforced films $\left(\mathrm{C}_{4.5}\right.$ $=4.5 \% \mathrm{w} / \mathrm{w}$ ). This last control was included to analyze the effects of the total solids content in the different materials properties.

Filler and Films Characterization. Both filler and films were examined by scanning electron microscopy (SEM), and infrared spectroscopy by Fourier transform with attenuated total reflectance (FTIR-ATR) was used in the identification of different compounds and the functional groups present in the samples, as well as their interactions. Moreover, film thickness, density, moisture color, UV barrier capacity and opacity, water vapor permeability, tensile resistance, and heat-sealing capacity were studied by methods described in previous works ${ }^{15,16}$ (for a detailed description, see the Supporting Information).

Biodegradation in Soil. Disintegration under soil composting conditions was studied using fertile soil as the substrate (moisture, 35-40\%; ash, 40-45\%; C/N ratio, 7.7; organic matter, 15-20\%; $\mathrm{pH}$ 6.2; and electrical conductivity, $1.1 \mathrm{mS} \mathrm{cm}^{-1}$ ), according to the methodology described in ASTM D5988-03. ${ }^{19}$ Films disks (4 cm of diameter) were buried at $5 \mathrm{~cm}$ depth from the surface to ensure aerobic degradation. The containers $\left(220 \mathrm{~cm}^{3}\right)$ were stored under controlled temperature and moisture conditions $\left(24.9 \pm 0.7^{\circ} \mathrm{C}\right.$ and $53 \pm 2.5 \% \mathrm{RH})$ and daily irrigated with distilled water to maintain soil moisture. Several authors have reported that weight variation is a good indicator of the degradability of polymeric materials; ${ }^{20-22}$ therefore, sample biodegradation was evaluated through weight loss (\%) monitoring of the samples throughout the degradation period: 7, $14,21,28,35$, and 42 days. In all cases, extracted samples were visually inspected and photographed.

To compare the degradation rate of the studied materials, the experimental results were fitted to the following sigmoid type model: ${ }^{20}$

$$
D_{\mathrm{t}}=\frac{D_{0}-D_{\infty}}{1+\mathrm{e}^{\left(\frac{t-t_{50}}{\mathrm{dt}}\right)}}+D_{\infty}
$$

where $D_{t}$ is the percentage of degradation evaluated by weight difference with the normalized initial condition, $D_{0}$ and $D_{\infty}$ are the initial and final degradation percentages considered as 0 and $100 \%$ respectively, $t_{50}$ represents the average time required for the degradation of $50 \%$ of the material, and $d t$ is an empirical parameter of adjustment that is related to the degradation kinetic rate.

Statistical Analysis. Multifactor analyses of variance were performed using InfoStat software. ${ }^{23}$ Differences in the properties of the films were determined by Fisher's Least Significant Difference (LSD) mean discrimination test, using a significance level of $\alpha=0.05$.

\section{RESULTS AND DISCUSSION}

Cassava bagasse was fractionated according to its particle size, and each fraction presented different compositions as was evidenced by SEM (Figure 1). In the $S$ fraction, where particles smaller than $53 \mu \mathrm{m}$ are included, a predominance of starch granules remaining from the extraction procedure were observed (Figure 1a). On the other hand, in the L fraction, remains of the parenchyma plant tissue with occluded starch granules prevail (Figure 1c), whereas the intermediate fraction (M) presented a composition similar to that of $\mathrm{L}$ differing clearly in the filler particle size, though a greater proportion of residual starch occluded between the cell tissue remains was observed (Figure 1b). Correspondingly, the infrared spectra confirmed the compositional differences of the different fractions of particle size analyzed (Figure $1 d-f$ ).

The particle size distribution and chemical composition of the cassava bagasse herein studied (F) was analyzed in a previous work, ${ }^{15}$ presenting a greater proportion of particles smaller than $53 \mu \mathrm{m}$ and a larger percentage of carbohydrates. Likewise, the smaller particles ( $S$ ) exhibited sharper bands, indicating a more homogeneous composition. The characteristic bands of cassava starch are observed presenting minor variations in the frequency and intensity of the bands, probably due to the presence of some other compounds from cellular tissues that are present in low concentrations. A wide band at $3300 \mathrm{~cm}^{-1}$, associated with inter- and intramolecular hydrogen bridge interactions between the $\mathrm{OH}$ groups of the polysaccharides, ${ }^{24-27}$ and another between 2850 and $2930 \mathrm{~cm}^{-1}$, corresponding to the stretching vibrations of $\mathrm{CH}$ bonds in the methyl and methylene groups thereof, , $^{24,25,27,28}$ are observed (Figure 1d). As detailed in Table S1, in the region 1700-1200 $\mathrm{cm}^{-1}$, vibrations associated with bound water and "free" water in starch are detected; however, when analyzing the different fractions spectra, as the residue particle size increases, band contributions corresponding to compounds from the cell wall of the parenchymal root tissue start to be observed. On the one hand, the spectra of all the fractions larger than $53 \mu \mathrm{m}$ present a small band close to $1734 \mathrm{~cm}^{-1}$, which presents greater intensity and lower frequencies for the $M$ fraction and all the fractions that conform it (Figure 1e). This band is attributed to the acetyl and uronic ester groups of the hemicelluloses and pectins or to the ester bond of the carboxylic group of the ferulic and p-coumaric acids of lignin and/or hemicellulose. ${ }^{26,29}$ A wide peak around $1651 \mathrm{~cm}^{-1}$ is observed in all fractions which is associated, as mentioned by numerous authors, with the modes of flexion of absorbed water and some contributions of the carboxylic groups of pectins and other minor carbohydrates present in the bagasse. ${ }^{27,28}$ However, as the particle size increases, the peak widens and shifts toward lower frequencies, and the growth of one shoulder at 1538 $\mathrm{cm}^{-1}$ was observed, which is associated with the presence of proteins. Likewise, for fractions with larger particles (M, L, and F) when the aforementioned peak is deconvoluted, two important contribution bands at 1641 and $1600 \mathrm{~cm}^{-1}$ were identified: the first one associated with the absorbed water flexion and minor carbohydrates carboxylic groups as in fraction $S$, and the second one correlated to the increasing contributions of the band at $1598 \mathrm{~cm}^{-1}$ ascribed to the skeletal stretch of lignin aromatic rings ${ }^{30}$ (Table S1 and Figure 1e). The fractions M, L, and F, as well as the minor fractions that comprise them, presented characteristic bands of cellulose and hemicellulose with certain shifts due to the superposition of bands at 1367,927 , and $897 \mathrm{~cm}^{-1}$, which correlate with peaks 1372, 910, and $897 \mathrm{~cm}^{-1}$ from $\mathrm{C}-\mathrm{H}$ groups bending in cellulose and hemicellulose and an $\mathrm{O}-\mathrm{H}$ group bending from $\beta$-glycosidic bonds in glucose (Table S1 and Figure 1f).

Regardless of its size, the polymer matrix was able to retain the filler particles forming continuous films, which were visually differentiated due to their coloration and transparency 
(Figure S1). The control samples were colorless and translucent (Figure S1a and b), while the reinforced films were more opaque with the larger the size of the filling used (Figure S1c, d, e, and f).

The visual observations correlate with the color parameters determination: $\mathrm{L}^{*}$ (luminosity), $\mathrm{C}^{*}$ (chroma), $\mathrm{h}^{\circ}$ (hue), and $\Delta E$ (color difference). The luminosity of the material decreased with the addition of larger particles, with no significant differences $(p>0.05)$ among the controls $\left(C_{3}\right.$ and $\mathrm{C}_{4,5}$ ) and the films reinforced with $S$ (Figure 2a). However,
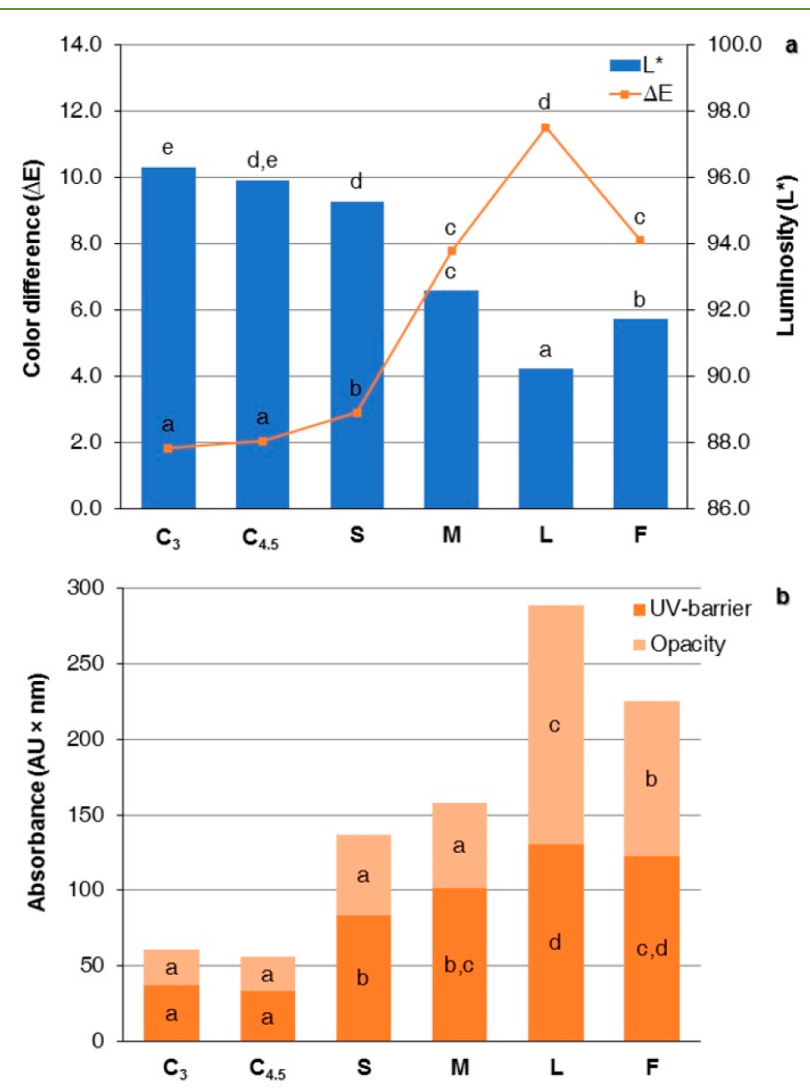

Figure 2. Color parameters and optical properties of cassava starch films reinforced with bagasse fractions of different particle sizes: (a) luminosity $\left(L^{*}\right)$ and color difference with respect to the white standard $(\Delta E)$ and (b) films UV-light barrier capacity (area under the curve between 200 and $400 \mathrm{~nm}$ ) and opacity (area under the curve between 400 and $700 \mathrm{~nm}$ ).

when larger filler particles are added, film luminosity significantly $(p<0.05)$ decreased, exhibiting the L films the lowest value. Accordingly, the greatest color differences were evidenced for films with $\mathrm{L}, \mathrm{F}$, and $\mathrm{M}$ fractions, respectively (Figure 2a). This parameter behavior correlates with the observed variations in brightness and the chromaticity parameters of the samples (hue and saturation, data not shown).

In regard to the optical barrier properties, the UV-visible spectra showed an increase in the absorbance of the composite materials with the incorporation of the filler, with this increment being greater for the $\mathrm{L}$ and $\mathrm{F}$ films (Figure $3 \mathrm{~b}$ ). Likewise, when compared to the control starch film, other authors have also reported an increase in starch-based composites opacity with filler content. ${ }^{31}$ Presumably, this effect results from a physical obstruction of the light by the particles, which is directly related to its size. In addition, the increase in the UV-barrier capacity of the composite films could be attributed to the presence of the phenolic compound characteristic of lignin present in the remaining parenchymal tissue predominant in the L, F, and $\mathrm{M}$ fractions of the bagasse.

The films SEM micrographs showed that in all cases the load was completely covered by the starch matrix (Figure 3 ), indicating the filler-polymer compatibility. ${ }^{32}$ However, in the materials containing larger bagasse particles ( $\mathrm{L}$ and $\mathrm{F}$ ), the images reveal the heterogeneity in the films thickness, resulting in rougher surfaces which was reflected in the high standard deviation values for these samples thickness (Table 1). In this way, the thickness of the materials increased with the particle size of the filling (Table 1).

However, it is noteworthy that regardless of the composition, no pores or cracks were observed in the surface or the cross section of the materials, which would drastically affect their mechanical and barrier characteristics.

Likewise, the FTIR-ATR spectra did not show substantial differences (Figure S2), observing the characteristic peaks of starch as detailed in Table S1. Analogous to the bagasse fractions, the spectra of the films showed a broad band in the region $3500-3000 \mathrm{~cm}^{-1}$, corresponding to hydrogen bonding interactions both between the components of the matrix and with the water bound to it, evidencing its compatibility. As expected, the spectra of the films presented a greater area and intensity of this band due to the greater number of interactions involved in the formation of the polymeric matrix. The main differences are observed in the region of the carbohydrate fingerprint, in which the vibrations of the $\mathrm{C}-\mathrm{O}-\mathrm{C}$ and $\mathrm{C}-\mathrm{O}-$ $\mathrm{H}$ bonds of the glycosidic ring are evident. In this area, the differences between the control and reinforced samples (mainly fractions F, M, and L) are attributed to the presence of the different components of the cell wall: cellulose, hemicellulose/arabinoxylans, xyloglucans, pectin, and lignin, among others.

In regard to film end properties, results are summarized in Table 1. As expected, composite materials presented significantly $(p<0.05)$ lower density than starch-based control films with the same total solid content $\left(\mathrm{C}_{4,5}\right)$. Films with smallsized particle fillers $(\mathrm{S})$ presented a similar density than control films $\left(\mathrm{C}_{3}\right)$ presumably due to its greater proportion of starch granules (Figure 1a). For larger particles, density decreases with bagasse particle size fraction $(M>L)$. In this regard, $F$ biocomposites presented the lowest density values. This effect could be attributed how filler particles with different sizes fit within the starch matrix, probably giving place to less clustered and therefore lighter structures. These results are in accordance to those reported by other authors working on different starch-based biocomposites. ${ }^{33,34}$

In comparison, even though no pores or cracks were detected by SEM (Figure 3), the water vapor permeability (WVP) of the films was significantly $(p<0.05)$ higher for the large particle size films $(\mathrm{L})$. These results were attributed to the discontinuities in the material matrix structure, although the bagasse particles were completely covered by the starch matrix when only large particles are included. Also, L films present the greater standard deviations in films thickness values (Figure $3 \mathrm{e}$ and Table 1). In the same way, these discontinuities that constitute points of tension in the material could be responsible for the decrease in the tensile strength and the modulus of elasticity of the same (Table 1 ). The permeability decreases with the particle size of the filler $(L>M>S>C)$, similar to that of the films that contain all the bagasse fractions 

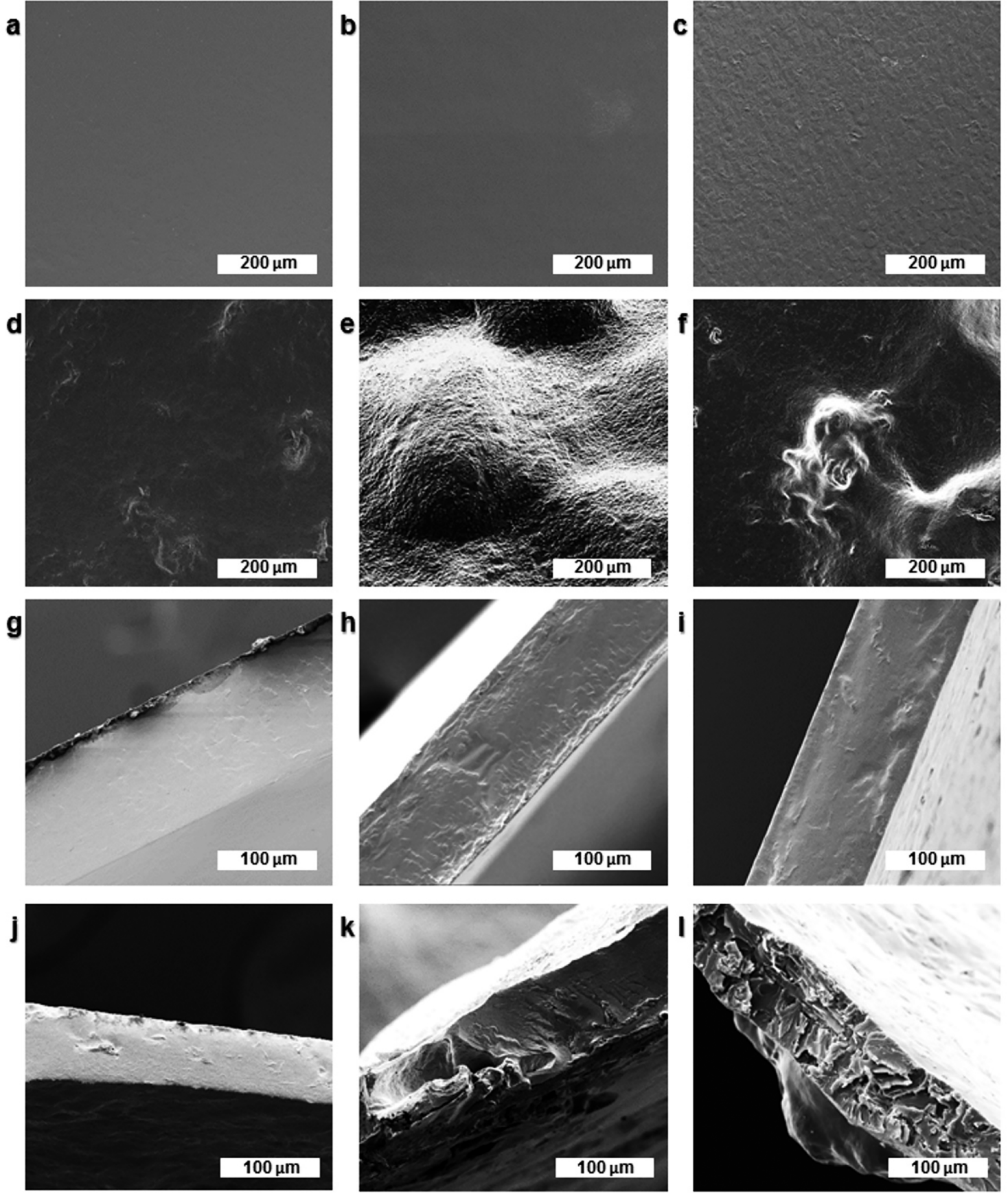

Figure 3. SEM micrographs of cassava starch films reinforced with bagasse fractions of different particle size: surface images at $500 \times$ from samples $\mathrm{C}_{3}(\mathrm{a}), \mathrm{C}_{4.5}(\mathrm{~b}), \mathrm{S}(\mathrm{c}), \mathrm{M}(\mathrm{d}), \mathrm{L}(\mathrm{e})$, and F (f) and cross sections $1000 \times$ of samples $\mathrm{C}_{3}(\mathrm{~g}), \mathrm{C}_{4.5}(\mathrm{~h}), \mathrm{S}(\mathrm{i}), \mathrm{M}(\mathrm{j}), \mathrm{L}(\mathrm{k})$, and F (l).

(F). The control with the same solids content as the composite materials $\left(\mathrm{C}_{4,5}\right)$ presented a slightly higher WVP than the $\mathrm{C}_{3}$ control. The obtained WVP values are within the range of those reported by other authors for other polysaccharides films. $^{35,36}$

As shown in Table 1, films with $\mathrm{F}$ and $\mathrm{S}$ particles improved the tensile strength of the material, although they reduced the film flexibility, while the medium-sized particles (M) reinforced the matrix with less impact on the elongation. These mechanical properties enhancement in $M$ samples are thought to be a consequence of a balance between parenchymal tissue content and particle size of this bagasse fraction giving place to thicker, stronger, and more flexible materials. On the contrary, composites containing L particles presented the lowest elongation at break, attributed to the discontinuities previously mentioned. Although the starch control films $\left(\mathrm{C}_{3}\right)$ showed a high percentage of elongation at break due to the more efficient plasticizing effect of glycerol on this matrix, its mechanical properties are poor. The reinforcing effect of natural fibers has been extensively discussed in the literature; thus, it should be noted that these results are within the range of those reported for other starch-based biocomposites. ${ }^{37,38}$ In general, and as expected, the mechanical characteristics of the $S$ films and the $C_{4,5}$ control are similar due to the high starch content of the $S$ fraction. This same trend was also observed for water vapor barrier properties (Table 1). 
Table 1. Thickness, Moisture Content, Water Vapor Barrier, and Mechanical Resistance to Tensile Test and Heat-Sealing of Cassava Starch-Based Materials Reinforced with 1.5\% W/W of Different Particle-Sized Fractions of Cassava Starch Bagasse ${ }^{a}$

\begin{tabular}{|c|c|c|c|c|c|c|c|c|c|}
\hline \multirow[b]{2}{*}{ Film } & \multirow[b]{2}{*}{$\begin{array}{l}\text { Thickness } \\
(\mu \mathrm{m})\end{array}$} & \multirow[b]{2}{*}{$\begin{array}{l}\text { Density } \\
\left(\mathrm{g} / \mathrm{cm}^{3}\right)\end{array}$} & \multirow[b]{2}{*}{$\begin{array}{l}\text { Moisture } \\
(\%)\end{array}$} & \multirow[b]{2}{*}{$\begin{array}{l}\mathrm{WVP} \times 10^{11} \\
(\mathrm{~g} / \mathrm{m} \mathrm{s} \mathrm{Pa})\end{array}$} & \multicolumn{3}{|c|}{ Tensile mechanical resistance } & \multicolumn{2}{|c|}{ Seal strength } \\
\hline & & & & & $\begin{array}{c}\text { Tensile } \\
\text { strength } \\
(\mathrm{MPa})\end{array}$ & $\begin{array}{c}\text { Elongation at } \\
\text { break }(\%)\end{array}$ & $\begin{array}{l}\text { Elastic } \\
\text { modulus } \\
(\mathrm{MPa})\end{array}$ & $\begin{array}{l}\text { Max. seal } \\
\text { resistance } \\
(\mathrm{MPa})\end{array}$ & $\begin{array}{l}\text { Energy to break } \\
\text { the seal }\left(\mathrm{kJ} / \mathrm{m}^{3}\right)\end{array}$ \\
\hline $\mathrm{C}_{3}$ & $92.7 \pm 9^{a}$ & $1.48 \pm 0.02^{\mathrm{d}}$ & $20.3 \pm 1.9^{b}$ & $10.66 \pm 2.4^{\mathrm{a}}$ & $1.3 \pm 0.1^{\mathrm{a}}$ & $35.8 \pm 10.7^{c}$ & $505 \pm 173^{\mathrm{ab}}$ & $1.7 \pm 0.5^{\mathrm{a}}$ & $1154 \pm 337^{d}$ \\
\hline $\mathrm{C}_{4,5}$ & $130.5 \pm 5^{b}$ & $1.56 \pm 0.01^{\mathrm{e}}$ & $12.5 \pm 1.7^{\mathrm{a}}$ & $15.39 \pm 2.0^{\mathrm{bc}}$ & $11.3 \pm 3.3^{c}$ & $11.3 \pm 5.4^{\mathrm{ab}}$ & $757 \pm 38^{\mathrm{abc}}$ & $2.2 \pm 0.8^{\mathrm{ab}}$ & $162 \pm 52^{\mathrm{ab}}$ \\
\hline$S$ & $124.5 \pm 8^{\mathrm{b}}$ & $1.47 \pm 0.02^{\mathrm{d}}$ & $12.6 \pm 0.2^{\mathrm{a}}$ & $13.36 \pm 0.5^{\mathrm{ab}}$ & $16.3 \pm 2.4^{\mathrm{de}}$ & $7.5 \pm 1.2^{\mathrm{ab}}$ & $3028 \pm 701^{\mathrm{d}}$ & $1.4 \pm 0.9^{\mathrm{a}}$ & $29 \pm 10^{\mathrm{a}}$ \\
\hline M & $133.6 \pm 8^{b}$ & $1.28 \pm 0.03^{c}$ & $13.7 \pm 1.8^{\mathrm{a}}$ & $17.93 \pm 2.3^{c}$ & $20.2 \pm 5.3^{\mathrm{e}}$ & $13.1 \pm 5.4^{\mathrm{b}}$ & $1033 \pm 25^{\mathrm{bc}}$ & $5.7 \pm 0.7^{c}$ & $389 \pm 105^{\mathrm{c}}$ \\
\hline $\mathrm{L}$ & $184.2 \pm 14^{\mathrm{c}}$ & $1.05 \pm 0.01^{\mathrm{b}}$ & $11.2 \pm 0.1^{\mathrm{a}}$ & $35.77 \pm 1.5^{\mathrm{d}}$ & $6.7 \pm 1.7^{\mathrm{b}}$ & $5.7 \pm 2.1^{\mathrm{a}}$ & $195 \pm 18^{\mathrm{a}}$ & $2.2 \pm 0.5^{\mathrm{ab}}$ & $157 \pm 40^{\mathrm{b}}$ \\
\hline $\mathrm{F}$ & $177.5 \pm 20^{c}$ & $0.79 \pm 0.03^{\mathrm{a}}$ & $13.4 \pm 0.8^{\mathrm{a}}$ & $14.61 \pm 0.7^{\mathrm{ab}}$ & $14.7 \pm 2.1^{\mathrm{d}}$ & $5.8 \pm 1.9^{\mathrm{a}}$ & $1247 \pm 35^{\mathrm{c}}$ & $3.4 \pm 0.5^{\mathrm{b}}$ & $62 \pm 16^{\mathrm{ab}}$ \\
\hline
\end{tabular}

${ }^{a}$ Reported values correspond to the mean \pm standard deviation. Different letters within the same column indicate significant differences $(p<0.05)$. WVP is water vapor permeability.

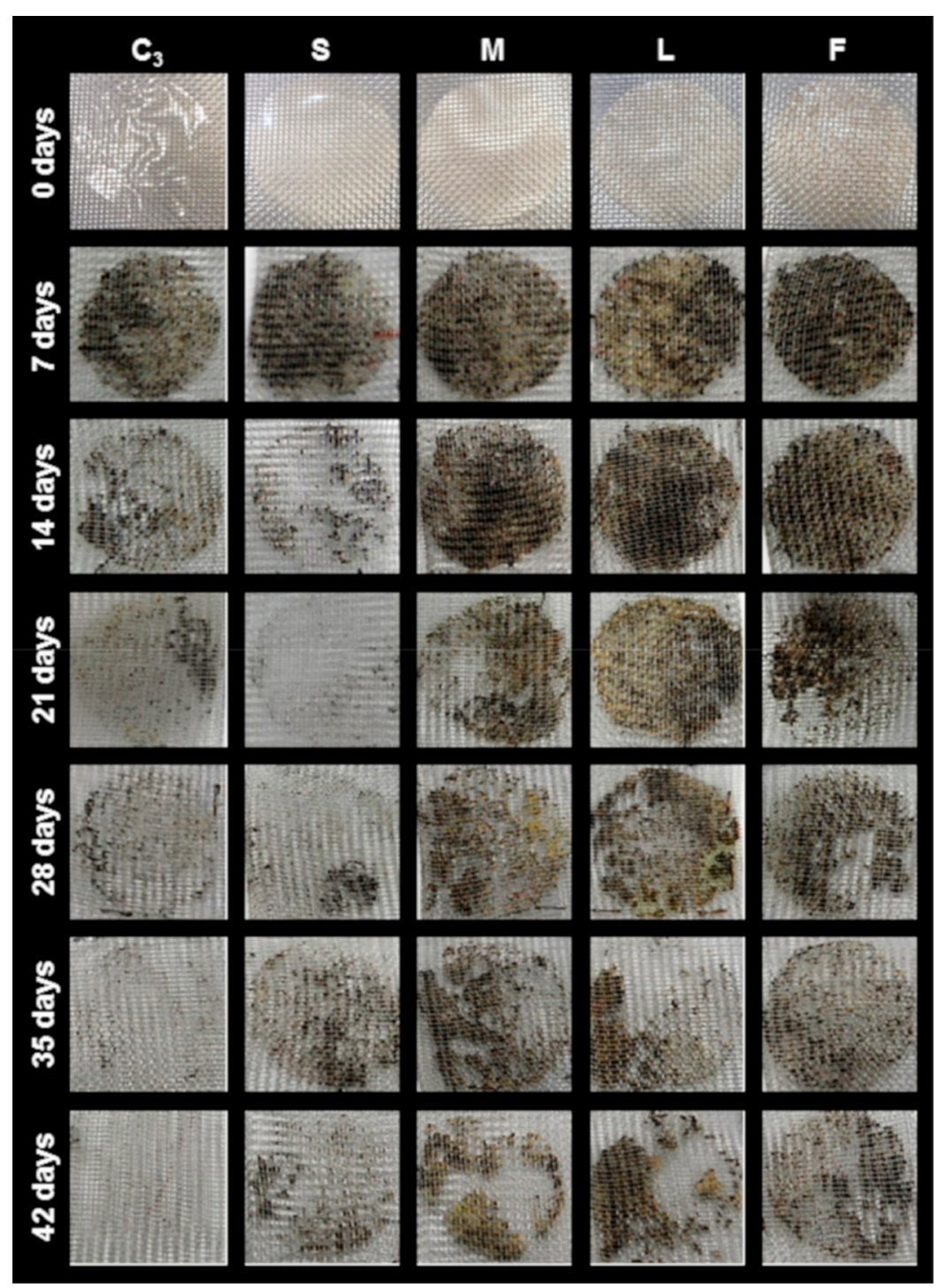

Figure 4. Photographic follow-up of soil biodegradation process of films reinforced with different particle sizes of bagasse along a 42 day long assay.

All films were successfully heat sealed by the impulse technique, widely used in the case of flexible synthetic materials. ${ }^{39}$ In accordance with the standard failure modes described in ASTM F 88-00, ${ }^{40}$ sealed films typically broke near the closure indicating that the mechanical strength of the seal is greater than that of the material. However, reinforced films presented, in general, greater resistance to sealing than control and higher than those reported for corn starch films by López et $\mathrm{al}^{41}$ Compared with synthetic materials though, fiberreinforced films exhibited lower resistance to sealing since the values obtained were $63.0 \pm 11.6$ and $4.0 \pm 0.6 \mathrm{MPa}$ for low density polyethylene (LDPE) and for reinforced cassava starch films (F), respectively (for the test description, see the Supporting Information). 
It should be noted that the observed variations in the behavior of $\mathrm{C}_{4.5}$ films can be explained considering that the failure mode was not uniform in all cases, even though the number of replicates analyzed for this sample was higher than the rest ( 20 vs 15 replicates).

In summary, the loading particle size had a substantial effect on the mechanical, barrier, and optical properties of the composite materials based on cassava starch. As expected, the reinforced films with a particle size of less than $500 \mu \mathrm{m}(\mathrm{F})$ showed an intermediate behavior to that of the films containing fillers with different fractions of the bagasse $(\mathrm{L}$, $\mathrm{M}$, and S), probably due to a combination of its individual effects on the matrix.

In addition, an integral study of the biodegradation process was carried out, making a photographic, gravimetric, and microscopic follow-up. Figure 4 shows the sequence of photographs of soil biodegradation of composite films reinforced with different particle size and no-load control. In this test, only the $\mathrm{C}_{3}$ control was included due to the high number of samples that should be evaluated, and the mechanical behavior and barrier properties of the $\mathrm{C}_{4.5}$ control were statistically comparable to that of the $S$ films.

In an analogous way it was observed by scanning electron microscopy (Figure S3) that after 15 days the degradation of the films with smaller particles ( $M$ and $S$ ) and the control is mainly due to the erosion and mechanical degradation of the sample, while in the films containing $\mathrm{L}$ and $\mathrm{F}$ fractions some hyphae were observed, which indicated the colonization of fungi coming from the soil (Figure S3). However, at higher times, all the tested materials showed an important microbial degradation.

Table 2 shows the results obtained from the weight loss data fitting to the Boltzmann model. In all cases, the adjustment was

Table 2. Biodegradation Kinetics Empirical Parameters of Cassava Starch-Based Films Reinforced with Cassava Bagasse Filler Particles of Different Size ${ }^{a}$

$\begin{array}{lccc}\text { Film } & t_{50}(\text { days }) & d t \text { (days) } & r^{2} \\ \mathrm{C}_{3} & 14.51 \pm 1.36^{\mathrm{a}} & 5.91 \pm 1.33^{\mathrm{a}} & 0.9099 \\ \mathrm{~S} & 12.41 \pm 2.09^{\mathrm{a}} & 4.09 \pm 1.72^{\mathrm{a}} & 0.8129 \\ \mathrm{M} & 24.82 \pm 1.55^{\mathrm{b}} & 10.68 \pm 1.53^{\mathrm{b}} & 0.9312 \\ \mathrm{~L} & 23.80 \pm 2.35^{\mathrm{b}} & 11.33 \pm 2.58^{\mathrm{b}} & 0.8238 \\ \mathrm{~F} & 25.88 \pm 1.54^{\mathrm{b}} & 10.23 \pm 1.36^{\mathrm{b}} & 0.9242\end{array}$

${ }^{a}$ Reported values correspond to the mean \pm standard deviation. Different letters within the same column indicate significant differences $(p<0.05)$.

acceptable $\left(r^{2}>0.8129\right)$, although there is greater dispersion at longer times. The findings indicated that films reinforced with bagasse particles greater than $53 \mu \mathrm{m}(\mathrm{M}, \mathrm{L}$, and $\mathrm{F})$ have a significantly longer $t_{50}$ degradation time $(p<0.05)$ than that of the control or $S$ films. On the other hand, the empirical parameter of adjustment $d t$, which is inversely related to the speed of degradation of the material, presents an analogous behavior, indicating a delayed degradation of the reinforced materials: $\mathrm{M}, \mathrm{L}$, and F.

These results are correlated with the bagasse fractions composition and characterization by SEM and FTIR since they indicate that the $S$ fraction is basically constituted by starch remaining from the extraction process and therefore presents a behavior similar to the control film. Compared with other biodegradable polymers, other authors have reported similar and even lower average biodegradability times for PLA-PHB composite materials reinforced with cellulose nanocrystals ${ }^{20}$ or PLA reinforced with clays. ${ }^{42}$

Overall, these results would indicate the potential of these materials for agronomic purposes since degradation in soil of all the starch materials studied (reinforced and control) is guaranteed in less than 50 days, a key feature in applications such as soil cover or replanting pots. Moreover, the biodegradable nature of these materials and their ability to be thermally sealed could lead to the development of containers for specific food applications, such as the preservation of organic products.

Finally, the effect of the bagasse filler particle size impact on cassava starch-based biocomposites properties have been studied, showing that particles have a greater impact over different materials properties depending on their size and composition. Therefore, a greater UV-visible barrier capacity is attributed to the large particles charge $(\mathrm{L})$, while the mechanical properties improved mainly due to medium-sized particles (M) and the smaller particles fraction $(S)$ reduced the WVP with respect to the control (C3). Moreover, reinforced films with all the fractions (F) showed an intermediate behavior of that of films containing different fractions of bagasse ( $\mathrm{L}, \mathrm{M}$, and $\mathrm{S}$ ) with lower density. Considering these results, it would be important that future research on biocomposites thoroughly investigate the particle size distribution of the used filler since it may have important influence on the material's end of use properties.

\section{ASSOCIATED CONTENT}

\section{S Supporting Information}

The Supporting Information is available free of charge on the ACS Publications website at DOI: 10.1021/acssuschemeng.8b04700.

Experimental section, including scanning electron microscopy (SEM), infrared spectrophotometry by Fourier transform with attenuated total reflectance (FTIR-ATR), thickness, water content, color, UV barrier capacity and opacity, water vapor permeability (WVP), and mechanical properties measurements description. Table with main vibrations IR peaks assignment in the FTIR spectra of cassava starch and cassava byproducts. Figure including all cassava biocomposites FTIR-ATR spectra. Materials photographs and SEM micrographs of biodegraded films. (PDF)

\section{AUTHOR INFORMATION}

\section{Corresponding Authors}

*Telephone: +54 0221 4254853. Fax: +54 0221 4249287. Email: florencia.versino@ing.unlp.edu.ar (Florencia Versino).

*Telephone: +54 0221 4254853. Fax: +54 0221 4249287. Email: magarcia@quimica.unlp.edu.ar (Maria Alejandra García).

ORCID

Florencia Versino: 0000-0002-7866-5235

Notes

The authors declare no competing financial interest.

\section{ACKNOWLEDGMENTS}

This work was supported by the Agencia Nacional de Promoción Científica y Tecnológica (ANPCyT, Project PICT 2011-1213, and 2015-0921) and the Consejo Nacional 
de Investigaciones Científicas y Técnicas (CONICET). Florencia Versino thanks CONICET as well for a Doctoral and Postdoctoral Fellowship.

\section{REFERENCES}

(1) Avérous, L.; Le Digabel, F. Properties of biocomposites based on lignocellulosic fillers. Carbohydr. Polym. 2006, 66 (4), 480-493.

(2) Gurunathan, T.; Mohanty, S.; Nayak, S. K. A review of the recent developments in biocomposites based on natural fibres and their application perspectives. Composites, Part A 2015, 77, 1-25.

(3) Shalwan, A.; Yousif, B. F. In State of Art: Mechanical and tribological behaviour of polymeric comopistes based on natural fibres. Mater. Eng. 2013, 48 (1), 14-24.

(4) Sánchez-Safont, E. L.; Aldureid, A.; Lagarón, J. M.; Gámez-Pérez, J.; Cabedo, L. Biocomposites of different lignocellulosic wastes for sustainable food packaging applications. Composites, Part B 2018, 145, 215-225.

(5) Bassyouni, M.; Waheed ul Hasan, S. The Use of Rice Straw and Husk Fibers as Reinforcements in Composites. In Biofiber Reinforcements in Composite Materials; Faruk, O., Sain, M., Eds.; Elsevier, 2015; pp 385-422.

(6) Väisänen, T.; Das, O.; Tomppo, L. A review on new bio-based constituents for natural fiber-polymer composites. J. Cleaner Prod. 2017, 149, 582-596.

(7) Azwa, Z. N.; Yousif, B. F.; Manalo, A. C.; Karunasena, W. A review on the degradability of polymeric composites based on natural fibres. Mater. Eng. 2013, 47 (1), 424-442.

(8) Dittenber, D. B.; GangaRao, H. V. S. Critical review of recent publications on use of natural composites in infrastructure. Composites, Part A 2012, 43 (8), 1419-1429.

(9) Mohanty, A. K.; Misra, M.; Drzal, L. T. Sustainable BioComposites from Renewable Resources: Opportunities and Challenges in the Green Materials World. J. Polym. Environ. 2002, 10 (1/ 2), 19-26.

(10) Monteiro, S. N.; Calado, V.; Rodriguez, R. J. S.; Margem, F. M. Thermogravimetric behavior of natural fibers reinforced polymer composites-An overview. Mater. Sci. Eng., A 2012, 557, 17-28.

(11) Sanjay, M. R.; Madhu, P.; Jawaid, M.; Senthamaraikannan, P.; Senthil, S.; Pradeep, S. Characterization and properties of natural fiber polymer composites: A comprehensive review. J. Cleaner Prod. 2018, 172, 566-581.

(12) Yao, Z.; Heng, J. Y. Y.; Lanceros-Méndez, S.; Pegoretti, A.; Ji, X.; Hadjittofis, E.; Xia, M.; Wu, W.; Tang, J. Study on the surface properties of colored talc filler (CTF) and mechanical performance of CTF/acrylonitrile-butadiene-styrene composite. J. Alloys Compd. 2016, 676, 513-520.

(13) Haque, A.; Mondal, D.; Khan, I.; Usmani, M. A.; Bhat, A. H.; Gazal, U. Fabrication of composites reinforced with lignocellulosic materials from agricultural biomass. In Lignocellulosic Fibre and Biomass-Based Composite Materials. Processing, Properties and Applications; Jawaid, M., Tahir, P. M., Saba, N., Eds.; Woodhead Publisher: Duxford, UK, 2017; pp 179-191.

(14) Chen, Z.; Lin, N.; Gao, S.; Liu, C.; Huang, J.; Chang, P. R. Sustainable Composites from Biodegradable Polyester Modified with Camelina Meal: Synergistic Effects of Multicomponents on Ductility Enhancement. ACS Sustainable Chem. Eng. 2016, 4 (6), 3228-3234.

(15) Versino, F.; García, M. A. Cassava (Manihot esculenta) starch films reinforced with natural fibrous filler. Ind. Crops Prod. 2014, 58 (1), 305-314

(16) Versino, F.; López, O. V.; García, M. A. Sustainable use of cassava (Manihot esculenta) roots as raw material for biocomposites development. Ind. Crops Prod. 2015, 65, 79-89.

(17) Badia, J. D.; Gil-Castell, O.; Ribes-Greus, A. Long-term properties and end-of-life of polymers from renewable resources. Polym. Degrad. Stab. 2017, 137, 35-57.

(18) Lopez, O. V.; Versino, F.; Villar, M. A.; Garcia, M. A. Agroindustrial residue from starch extraction of Pachyrhizus ahipa as filler of thermoplastic corn starch films. Carbohydr. Polym. 2015, 134 (1), 324-32.

(19) ASTM D5988-03, Standard Test Method for Determining Aerobic Biodegradation in Soil of Plastic Materials or Residual Plastic Materials after Composting; ASTM International, West Conshohocken, PA, 2003. DOI: $10.1520 /$ D 5988-03.

(20) Arrieta, M. P.; Fortunati, E.; Dominici, F.; Rayón, E.; López, J.; Kenny, J. M. PLA-PHB/cellulose based films: Mechanical, barrier and disintegration properties. Polym. Degrad. Stab. 2014, 107 (1), 139149.

(21) Ishigaki, T.; Sugano, W.; Nakanishi, A.; Tateda, M.; Ike, M.; Fujita, M. The degradability of biodegradable plastics in aerobic and anaerobic waste landfill model reactors. Chemosphere 2004, 54 (3), $225-233$.

(22) Ludueña, L.; Vázquez, A.; Alvarez, V. Effect of lignocellulosic filler type and content on the behavior of polycaprolactone based ecocomposites for packaging applications. Carbohydr. Polym. 2012, 87 (1), 411-421.

(23) Di Rienzo, J. A.; Casanoves, F.; Balzarini, M. G.; Gonzalez, L.; Tablada, M.; Robledo, C. W. InfoStat, 2011.

(24) Zhang, Y.; Han, J. H. Mechanical and thermal characteristics of pea starch films plasticized with monosaccharides and polyols. J. Food Sci. 2006, 71 (2), E109-E118.

(25) Piermaria, J.; Bosch, A.; Pinotti, A.; Yantorno, O.; Garcia, M. A.; Abraham, A. G. Kefiran films plasticized with sugars and polyols: Water vapor barrier and mechanical properties in relation to their microstructure analyzed by ATR/FT-IR spectroscopy. Food Hydrocolloids 2011, 25, 1261-1269.

(26) Idrovo Encalada, A. M.; Basanta, M. F.; Fissore, E. N.; De'Nobili, M. D.; Rojas, A. M. Carrot fiber (CF) composite films for antioxidant preservation: Particle size effect. Carbohydr. Polym. 2016, 136, 1041-51.

(27) Bodirlau, R.; Teaca, C.-A.; Spiridon, I. Influence of natural fillers on the properties of starch-based biocomposite films. Composites, Part B 2013, 44 (1), 575-583.

(28) Ahuja, D.; Kaushik, A.; Singh, M. Simultaneous extraction of lignin and cellulose nanofibrils from waste jute bags using one pot pre-treatment. Int. J. Biol. Macromol. 2018, 107, 1294-1301.

(29) Kaushik, A.; Singh, M.; Verma, G. Green nanocomposites based on thermoplastic starch and steam exploded cellulose nanofibrils from wheat straw. Carbohydr. Polym. 2010, 82 (2), 337345 .

(30) Barana, D.; Ali, S. D.; Salanti, A.; Orlandi, M.; Castellani, L.; Hanel, T.; Zoia, L. Influence of Lignin Features on Thermal Stability and Mechanical Properties of Natural Rubber Compounds. ACS Sustainable Chem. Eng. 2016, 4 (10), 5258-5267.

(31) Castillo, L.; Lopez, O.; Lopez, C.; Zaritzky, N.; Garcia, M. A.; Barbosa, S.; Villar, M. Thermoplastic starch films reinforced with talc nanoparticles. Carbohydr. Polym. 2013, 95 (2), 664-674.

(32) Ibrahim, M. M.; Dufresne, A.; El-Zawawy, W. K.; Agblevor, F. A. Banana fibers and microfibrils as lignocellulosic reinforcements in polymer composites. Carbohydr. Polym. 2010, 81 (4), 811-819.

(33) Edhirej, A.; Sapuan, S. M.; Jawaid, M.; Zahari, N. I. Cassava/ sugar palm fiber reinforced cassava starch hybrid composites: Physical, thermal and structural properties. Int. J. Biol. Macromol. 2017, 101, 75-83.

(34) Ren, L.; Yan, X.; Zhou, J.; Tong, J.; Su, X. Influence of chitosan concentration on mechanical and barrier properties of corn starch/ chitosan films. Int. J. Biol. Macromol. 2017, 105 (3), 1636-1643.

(35) Jimenez, A.; Fabra, M. J.; Talens, P.; Chiralt, A. Polysaccharides as Valuable Materials in Food Packaging. In Functional Polymers in Food Science: From Technology to Biology, Vol. 1: Food Packaging; Cirillo, G., Spizzirri, U. G., Iemma, F., Eds.; Scrivener Publishing LLC: Beverly, MA, 2015, Vol. 1, pp 211-252.

(36) Müller, C. M. O.; Laurindo, J. B.; Yamashita, F. Effect of cellulose fibers addition on the mechanical properties and water vapor barrier of starch-based films. Food Hydrocolloids 2009, 23 (5), 13281333. 
(37) Ma, X.; Cheng, Y.; Qin, X.; Guo, T.; Deng, J.; Liu, X. Hydrophilic modification of cellulose nanocrystals improves the physicochemical properties of cassava starch-based nanocomposite films. LWT - Food Sci. Technol. 2017, 86, 318-326.

(38) Nawab, A.; Alam, F.; Haq, M. A.; Lutfi, Z.; Hasnain, A. Mango kernel starch-gum composite films: Physical, mechanical and barrier properties. Int. J. Biol. Macromol. 2017, 98, 869-876.

(39) Brody, A. L.; Marsh, K. S. The Wiley Encyclopedia of Packaging Technology, Second ed.; John Wiley \& Sons, Inc: New York, 1997; p 1023.

(40) ASTM F88-00, Standard Test Method for Seal Strength of Flexible Barrier Materials; ASTM International, West Conshohocken, PA, 2001. DOI: 10.1520/F0088-00.

(41) López, O. V.; Zaritzky, N. E.; Grossmann, M. V. E.; García, M. A. Acetylated and native corn starch blend films produced by blown extrusion. J. Food Eng. 2013, 116 (2), 286-297.

(42) Stloukal, P.; Pekarova, S.; Kalendova, A.; Mattausch, H.; Laske, S.; Holzer, C.; Chitu, L.; Bodner, S.; Maier, G.; Slouf, M.; Koutny, M. Kinetics and mechanism of the biodegradation of PLA/clay nanocomposites during thermophilic phase of composting process. Waste Manage. 2015, 42, 31-40. 